\title{
Biomechanical Assessment of the Influence of Inlay/Onlay Design and Material on Stress Distribution in Nonvital Molars
}

\author{
Ayham Darwich $^{1,2}$ Abeer Aljareh ${ }^{30}$ Omar Aladel ${ }^{3}$ Szabolcs Szávai ${ }^{4}$ Hasan Nazha ${ }^{4}$ \\ ${ }^{1}$ Department of Biomedical Engineering, Faculty of Biomedical \\ Engineering, Al-Andalus University for Medical Sciences, Tartous, Syria \\ 2 Department of Industrial Automation, Faculty of Technical \\ Address for correspondence Hasan Nazha, PhD, Faculty of \\ Mechanical Engineering and Informatics, University of Miskolc, \\ Miskolc, Hungary (e-mail: hasan.nazha@uni-miskolc.hu). \\ Engineering, University of Tartous, Tartous, Syria \\ ${ }^{3}$ Department of Fixed Prosthodontics, Faculty of Dentistry, Damascus \\ University, Damascus, Syria \\ ${ }^{4}$ Department of Machine and Product Design, Faculty of Mechanical \\ Engineering and Informatics, University of Miskolc, Miskolc, \\ Hungary \\ Eur J Gen Dent 2021;10:158-169.
}

\section{Abstract \\ Keywords \\ - inlay \\ - onlay \\ - restoration materials \\ - restoration design \\ - finite element analysis}

Objectives The aim of this study was to evaluate the influence of inlays/onlays with or without pulp extension from different materials on stress distribution in endodontically treated molars by three-dimensional finite element analysis (3D FEA).

Materials and Methods We used 3D mandibular molar models in this study. The models represented mesio-occluso-distal (MOD) cavities restored by inlays, onlays that covered buccal cusps, and onlays that covered all cusps with pulp extension (modified inlay/onlay) or without pulp extension (conventional inlay/onlay). Three materials (L: lithium disilicate glass-ceramic, P: polymer-infiltrated ceramic network [PICN], and C: nanofilled composite resin) were utilized. A force of $600 \mathrm{~N}$ was applied vertically and obliquely. Stress distribution in FEA models was analyzed using the von Mises theory. Results The results revealed that an oblique load generated higher stresses than vertical load. Composite resin restorations transmitted almost all the stress to the neighboring tooth structures, while lithium disilicate ceramic restorations absorbed most of the stresses. Moreover, modified inlays and onlays with pulp extension proved better than conventional inlays/onlays in terms of stress redistribution in dental structures. Onlays showed a better pattern of stress distribution than inlays within the restoration and the restored tooth.

Conclusions According to stress distribution in dental structures, modified lithium disilicate ceramic onlays with pulp extension have been found to be the best choice to restore endodontically treated molars among the studied restorations.
DOI https://doi.org/ 10.1055/s-0041-1736463. ISSN 2278-9626.

\footnotetext{
C 2021. European Journal of General Dentistry. All rights reserved. This is an open access article published by Thieme under the terms of the Creative Commons Attribution-NonDerivative-NonCommercial-License, permitting copying and reproduction so long as the original work is given appropriate credit. Contents may not be used for commercial purposes, or adapted, remixed, transformed or built upon. (https://creativecommons.org/ licenses/by-nc-nd/4.0/)

Thieme Medical and Scientific Publishers Pvt. Ltd., A-12, 2nd Floor, Sector 2, Noida-201301 UP, India
} 


\section{Introduction}

It is common to find a large mesio-occluso-distal (MOD) cavity with endodontic access in clinical practice. ${ }^{1}$ Endodontic treatment increases the fracture risk due to the loss of dental structures as well as the restorative procedures, especially in Class II cavities, such as MOD cavities. ${ }^{2}$ This decrease in fracture strength yields difficulty when choosing the best restoration for endodontically treated teeth, particularly posterior teeth. ${ }^{1}$ Full crowns with or without posts have been used widely ${ }^{3}$; they involve removing additional tooth structures. ${ }^{4}$ Moreover, posts are used only when more conservative solutions, such as inlays/onlays or full crowns with cores, are not available as the remaining coronal structures are insufficient to retain a core or a restoration. ${ }^{5}$ Endocrown is a total ceramic crown anchored both to the pulp chamber and on the cavity margins. ${ }^{6}$ It is an alternative restoration to full crowns with posts when the crown length is inadequate or the interocclusal space is not practically sufficient for suitable ceramic thickness. ${ }^{7}$ Inlay and onlay are two conservative restorations that might be used to restore vital teeth and endodontically treated teeth. ${ }^{8}$ Inlay is a fixed intracoronal restoration that does not cover any cusp, whereas onlay is a partial-coverage restoration that restores the occlusal surface and covers one or more cusps. ${ }^{9}$ They could be modified by extending to the pulp chamber in endodontically treated teeth. ${ }^{10}$

Even though inlay and onlay are considered conservative alternatives, ${ }^{11}$ the results of studies about their behavior are still controversial. Some authors concluded that cuspal coverage did not increase the fracture strength, and there was no difference between inlays and onlays. Holberg et al ${ }^{12}$ showed that the volume of ceramic inlays and preparation design did not affect stress distribution in the first mandibular molars. In contrast, other studies found that preparation design resulted in a significant difference. Dejak and Mlotkowski ${ }^{13}$ found that inlays were associated with unfavorable distribution and high magnitude of stresses, while onlays showed lower stresses and better distribution of stress than inlays. They also concluded that endocrowns caused more stress concentration in the remaining tooth structures than inlays and onlays. Moreover, Seow et $\mathrm{al}^{10}$ found that inlay and onlay with an extension to the pulp chamber did not offer any biomechanical advantage to the restored premolars when they were compared with inlay/onlay without pulp extension.

Inlay and onlay could be fabricated from different materials such as composite resin and ceramic. Composite resin provides a tooth-color restoration. ${ }^{14}$ The nanofillers in the composites promote physical properties such as high resistance to wear; they also provide superior optic and aesthetic properties, such as high translucency, high polish, and polish retention. ${ }^{15}$ Ceramic is another aesthetic restorative material. ${ }^{16}$ Lithium disilicate glass-ceramic (LDS) is characterized by its high translucency and physical properties due to the volume of lithium disilicate crystals and their needle-like shape. ${ }^{17}$ Polymer-infiltrated ceramic network (PICN) is another material that is considered as resin-matrix ceramic ${ }^{18}$; the PICN provides a lower tendency to brittle fracture than pure ceramic. ${ }^{19}$ Furthermore, it has a low level of abrasion on antagonizing teeth. ${ }^{19}$

A considerable number of studies showed contrasting results about the best restorative materials of inlay/onlay. For instance, some studies found the composite resin better than ceramic in terms of performance and fracture resistance. ${ }^{20,21}$ Liu et $\mathrm{al}^{21}$ found that the final fracture load of MOD composite inlays was higher than MOD ceramic inlays (2057.53 N and 2004.89 N, respectively). Magne and Oganesyan $^{22}$ concluded that ceramic was a better choice to provide more cusp stabilization when compared with composite resin. However, St-Georges et $\mathrm{al}^{23}$ showed no differences in fracture strength between ceramic and composite resin inlays.

The conflicting results of previous studies about inlay/onlay along with the lack of studies about inlay/onlay with a pulp extension led us to carry out this current study. Thus, the main aim of this study was to evaluate the influence of conventional inlays/onlays without pulp extension and modified inlays/onlays with an extension to the pulp chamber and their materials on stress distribution in endodontically treated molars, when vertical and oblique forces were applied, using three-dimensional finite element analysis (3D FEA).

\section{Materials and Methods}

\section{Modelling and Meshing}

This study was performed using a 3D FEA, which was based on computer geometry design. First, a series of cone-beam computed tomographic (CBCT) slices of the mandibular left first molar was taken (Pax-i3D Green; Vatech, Gyeonggi-do, Seoul, South Korea). Then, the slices were imported into the Mimics 21.0 software (Materialise NV Technologielaan; Leuven, Belgium) to isolate the components: enamel, dentin, and pulp. Using the 3-Matic software (Materialise NV Technologielaan; Leuven, Belgium), the periodontal ligament was created with a thickness of $0.25 \mathrm{~mm} .{ }^{8,24,25}$ The 3D objects were converted into STL files, which were then refined using the Geomagic software (Geomagic Studio; Geomagic Inc, USA). SolidWorks software (Dassault Systèmes SolidWorks Corporation, Waltham, USA) was also used to produce the inlay/onlay cavity preparations, cortical and spongy bones according to the dimensions taken from the literature. ${ }^{4,24,26}$ All models, as shown in - Figs. 1 and 2, were then exported to the Ansys Workbench 20.0 R2 software (Ansys Inc; Canonsburg, Pennsylvania, USA) to perform the FEA. A mesh of tetrahedral elements was generated for each model because of the complexity of the geometry. Then, it was refined as shown in - Fig. 3 and accepted with relative errors of less than $1 \%$. Details of nodes and elements are cited in - Table 1.

\section{Preparation and Restoration Design}

The preparation designs were created as described in the literature. ${ }^{4}$ The prepared cavity was two-thirds of the intercuspal distance with a 10-degree divergence of the internal walls. The depth of the occlusal cavity was $2.0 \mathrm{~mm}$ while the 

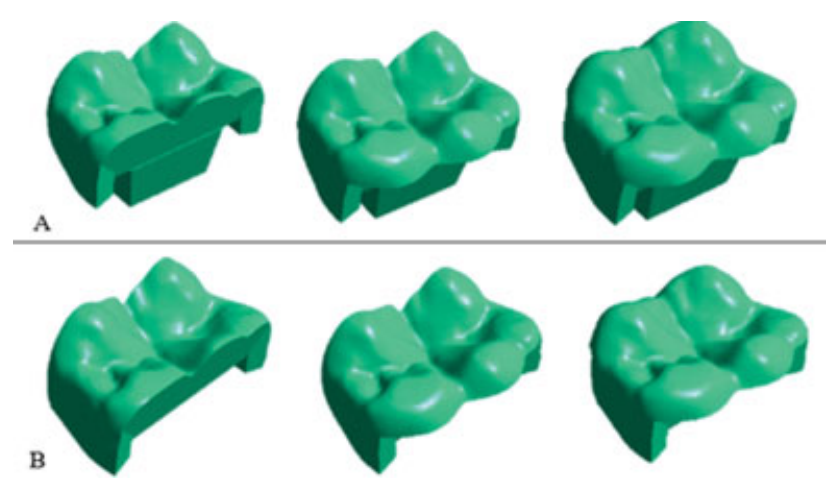

Fig. 1 Studied models. (A) modified restorations with pulp extension (inlay and onlay that covered buccal cusps and onlay that covered all cusps) from left to right. (B) Conventional restorations without pulp extension (inlay and onlay that covered buccal cusps and onlay that covered all cusps) from left to right.

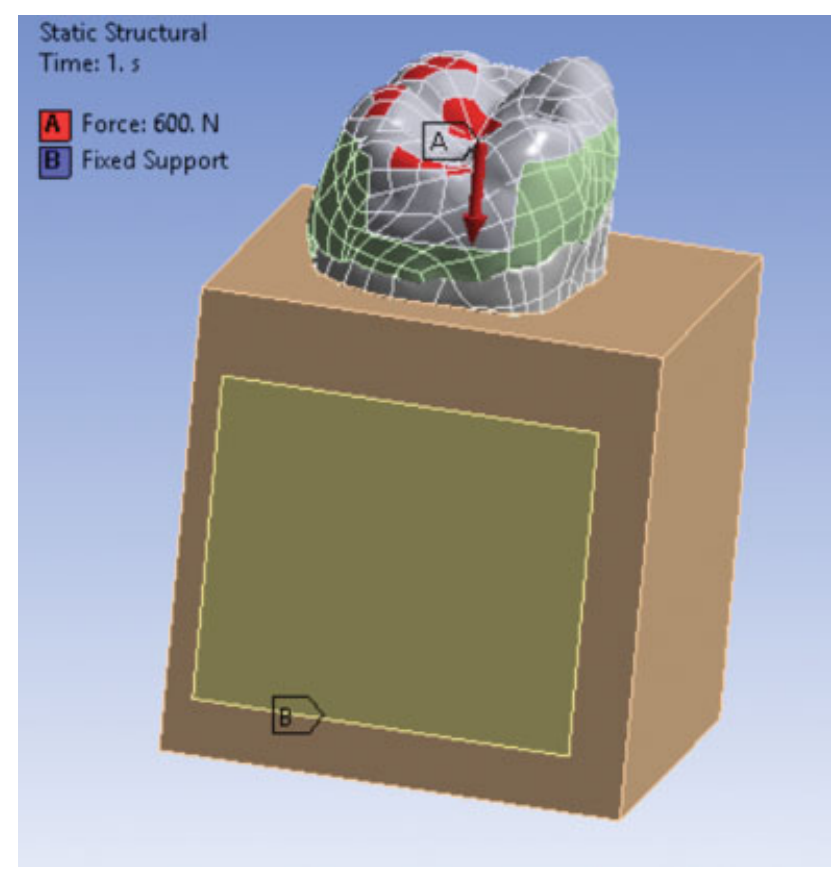

Fig. 2 FEA assembled model with loading points.

pulp chamber was $3.0 \mathrm{~mm}$ in depth. ${ }^{4}$ In the onlay models, only functional cusps or both functional and non-functional cusps were reduced $1.5 \mathrm{~mm}$ and $1.0 \mathrm{~mm}$, respectively. The study included three restorative materials: L: IPS e.max CAD

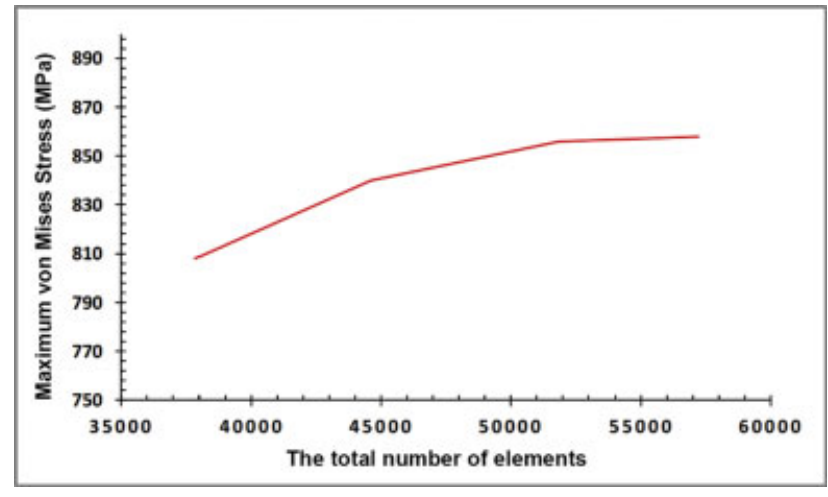

Fig. 3 Mesh sensitivity.

lithium disilicate glass-ceramic (LDS); P: Vita Enamic $®$ polymer-infiltrated ceramic network (PICN); C: Filtek ${ }^{\mathrm{TM}}$ supreme nanocomposite resin.

The models according to the restoration design were as follows: first, conventional inlay without pulp extension; second, conventional onlay that covered buccal cusps without pulp extension; third, conventional onlay that covered all cusps without pulp extension; fourth, modified inlay with pulp extension; fifth, modified onlay that covered buccal cusps with pulp extension; and finally, modified onlay that covered all cusps with pulp extension as shown in - Fig. $\mathbf{1}$.

A block of resin-modified glass ionomer cement (RMGI) was created to fill the pulp chamber in conventional inlay/onlay without pulp extension models. RMGI was selected in this study to represent a bonded restoration instead of composite resin ${ }^{10}$ in order for the results of conventional nanocomposite inlay/onlay not to interfere with the results of modified nanocomposite inlay/onlay with pulp extension, as a pulp chamber would be filled with composite resin in conventional and modified nanocomposite resin inlay/onlay models.

\section{Material Properties}

All materials were assumed to be isotropic, homogeneous, and linear elastic. The mechanical properties of all materials used in this study are taken from the literature. ${ }^{14,27-31} \mathrm{~A}$ summary of the mechanical properties is shown in -Table 2 .

\section{Boundary Conditions}

The models were fixed at the inferior surface of the cortical bone in all directions. Vertical and oblique static occlusal loadings of $600 \mathrm{~N}$ were applied on buccal cusps tips, central

Table 1 Number of nodes and elements in the models

\begin{tabular}{|l|l|l|}
\hline Model & Elements & Nodes \\
\hline Conventional inlay (L1, P1, C1) & 45,331 & 84,008 \\
\hline Conventional onlay/buccal cusps coverage (L2, P2, C2) & 46,657 & 89,916 \\
\hline Conventional onlay/all cusps coverage (L3, P3, C3) & 51,291 & 96,692 \\
\hline Modified inlay (L4, P4, C4) & 57,193 & 105,548 \\
\hline Modified onlay/buccal cusps coverage (L5, P5, C5) & 54,306 & 98,261 \\
\hline Modified onlay/all cusps coverage (L6, P6, C6) & 57,219 & 102,828 \\
\hline
\end{tabular}


Table 2 Mechanical properties of the materials used in the FE models

\begin{tabular}{|l|l|l|l|l|}
\hline Material & Poisson's ratio & Young's modulus (GPa) & Density $\left(\mathbf{g} / \mathbf{c m}^{3}\right)$ & References \\
\hline Enamel & 0.33 & 84 & 2.8 & 14 \\
\hline Dentin & 0.30 & 18.6 & 2.0 & 14 \\
\hline Gutta percha & 0.45 & 0.00069 & - & 27 \\
\hline Periodontal ligament & 0.069 & 0.45 & 1.1 & 1.3 \\
\hline Cortical bone & 0.30 & 13.7 & 1.3 & 14 \\
\hline Spongy bone & 0.30 & 13.7 & 2.47 & 14 \\
\hline Lithium disilicate glass ceramic & 0.21 & 83.5 & 2.14 & 28 \\
\hline Polymer-infiltrated ceramic network & 0.23 & 30 & 2.51 & 28 \\
\hline Resin modified glass ionomer cement & 0.30 & 4 & 1.98 & 29 \\
\hline Nanofill composite resin & 0.35 & 12.7 & 30,31 \\
\hline
\end{tabular}

fossa, and distal marginal ridge (-Fig. 2). ${ }^{14,31}$ The vertical loading was parallel to the longitudinal axis of the tooth acting like a normal loading, while the second loading was oblique, 45 degrees to the longitudinal axis to stimulate the force acting on the mandibular molar during the closing phase of the mastication cycle. ${ }^{14}$ Equivalent von Mises stress, based on the distortion energy theory, has been used in plenty of studies to evaluate different restorations from diverse materials including ceramic materials and composite resins. ${ }^{8,32-34}$ Thus, equivalent von Mises stresses were adopted to evaluate stress distribution in all models in the present study.

\section{Results}

\section{Stress distribution in restorations}

The maximum values of von Mises stress in enamel, dentin, and restoration are summarized in -Figs. 4-6. The maximum stress concentration occurred in the loading points: in the buccal cusps and the distal marginal ridge of the restoration as shown in - Figs. 7-10. Oblique loading was associated with a much higher stress concentration that lied on a large space of the occlusal surface, as shown in - Fig. 11. Regardless of loading direction, stress concentration increased within conventional inlay/onlay (without pulp extension), particularly in the internal surfaces of the restoration, when compared with modified inlay/onlay with pulp extension as shown in -Figs. 7-11.

Von Mises values in inlays were the highest when vertical loading was applied, while oblique loading was associated with the highest von Mises values within onlays that covered all cusps. Oblique loading also caused higher values in all restorations than vertical loading as shown in - Fig. 6.

Under both loading conditions, onlays showed better stress distribution than inlays as shown in -Figs. 7-11. Stress distribution in onlays that covered buccal cusps and onlays that covered all cusps was similar as shown in - Figs. 8 and $\mathbf{1 0}$.

\section{Stress Distribution in Enamel and Dentin}

Visual maps shown in - Figs. 12 and $\mathbf{1 3}$ showed that the stress in enamel concentrated in the loading areas on buccal cusps, the cervical region and the axial internal walls of the occlusal cavity. Oblique loading caused higher von Mises

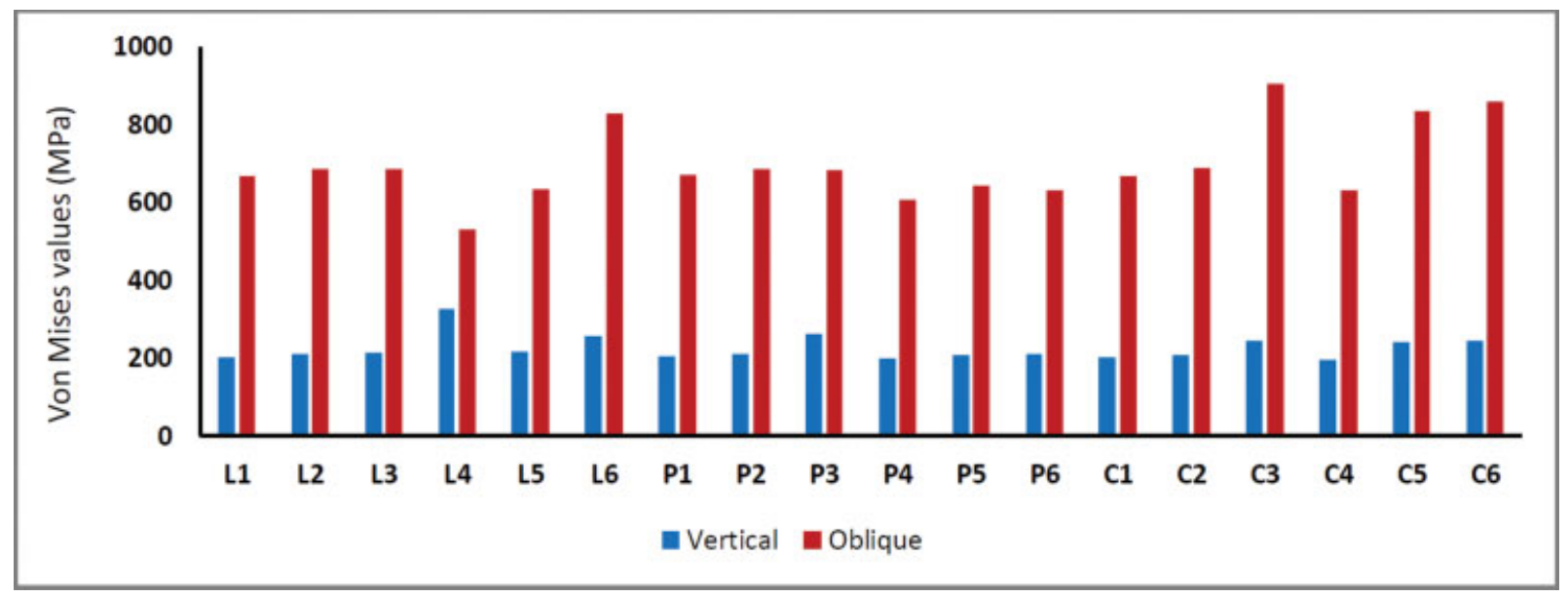

Fig. 4 Von Mises values in enamel when vertical and oblique loads were applied (L1, L2, L3: conventional LDS: inlay, onlay covered buccal cusps, onlay covered all cusps models, respectively. L4, L5, L6: modified LDS: inlay, onlay covered buccal cusps, onlay covered all cusps models, respectively. P1-P6: PICN restoration models in the same previous order. C1-C6: nanocomposite resin restoration models in the same order). 


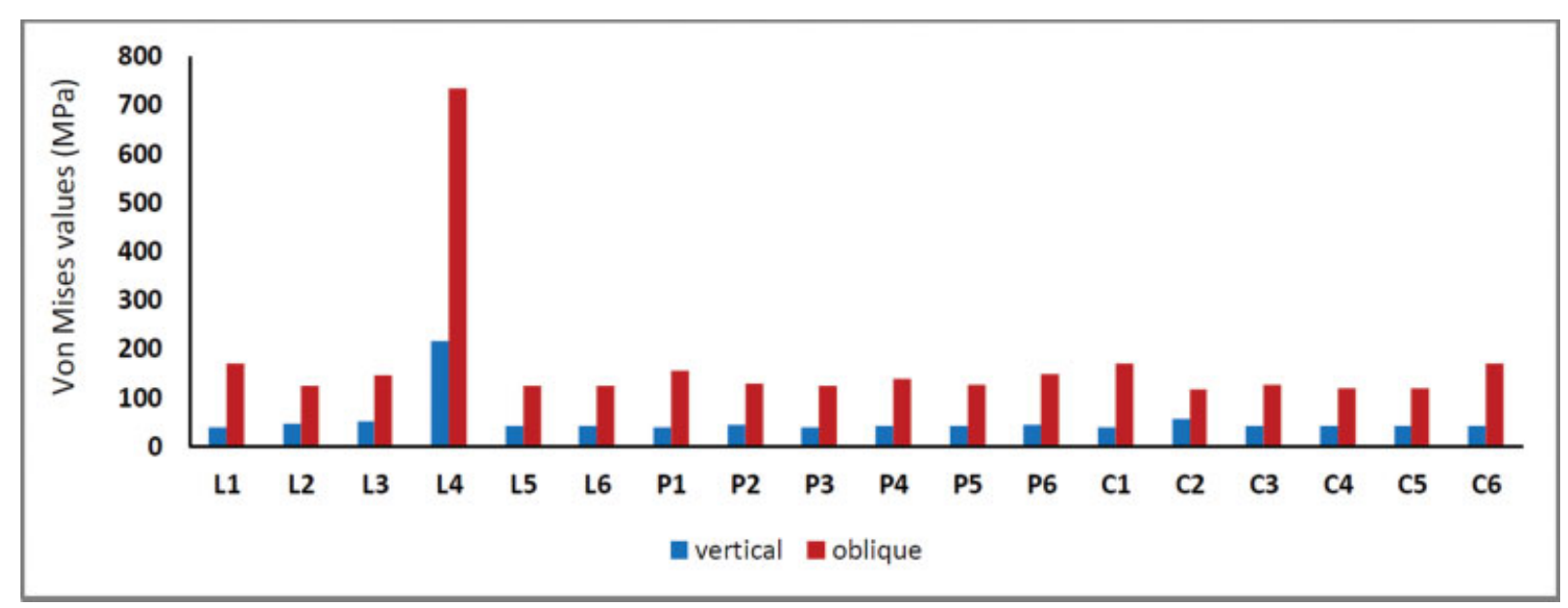

Fig. 5 Von Mises values in dentin when vertical and oblique loads were applied; L1-L6: LDS restoration models. P1-P6: PICN restoration models. C1-C6: nanocomposite resin restoration models.

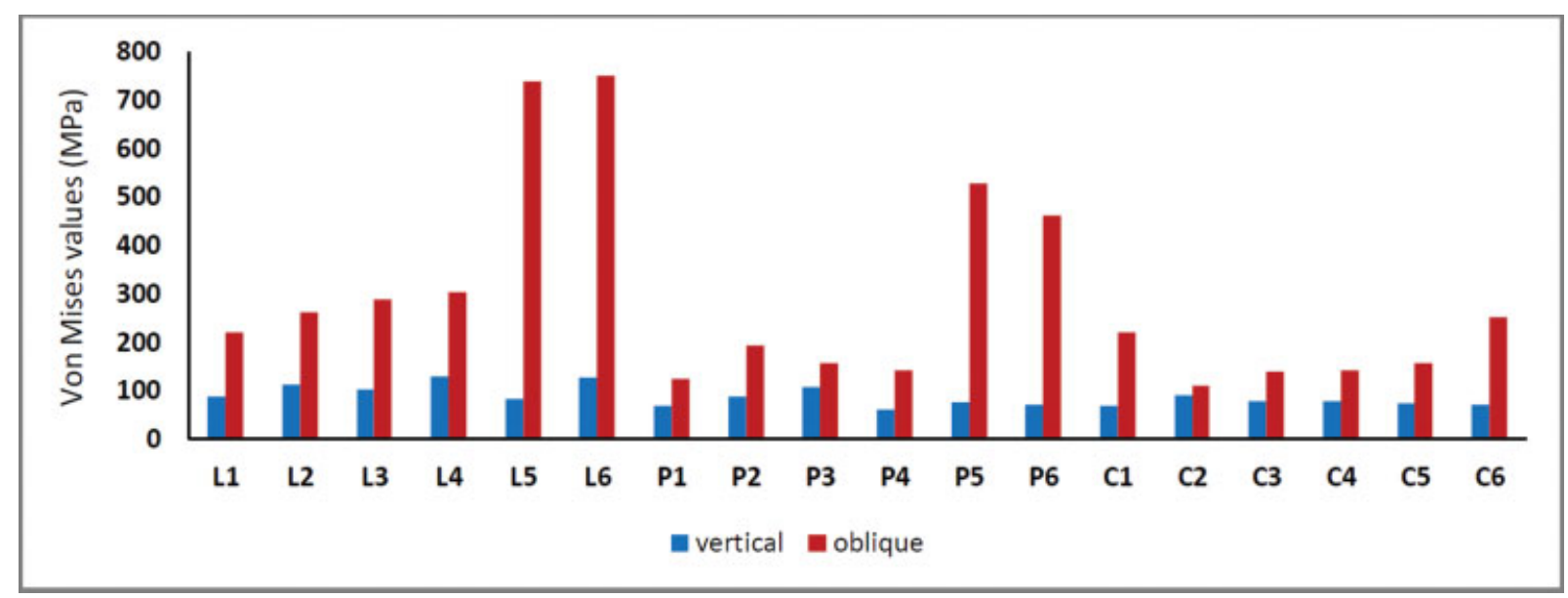

Fig. 6 Von Mises values in restorations when vertical and oblique loads were applied; L1-L6: LDS restorations. P1-P6: PICN restorations. C1-C6: nanocomposite resin restorations.

values as well as higher stresses that concentrated in enamel as shown in -Fig. 4 and -Fig. 13 (D-F).

In dentin, vertical loading caused stress concentration in the cervical region and the buccal axial wall of both the occlusal cavity and the pulp chamber, while oblique loading led to greater stress concentration in the previous areas as well as the lingual axial wall of the occlusal cavity as shown in -Figs. 12 and 13. It also caused more stress concentration in root surfaces than vertical loading as observed in - Fig. 13. Inlay models showed higher stress concentration in the internal walls of preparation than onlay models as shown in - Fig. 12 with higher von Mises values in enamel and dentin as noticed in -Figs. $\mathbf{4}$ and $\mathbf{5}$. The stress distribution pattern in dental structures restored by modified inlay/onlay with pulp extension was better than the stress in inlay/onlay without pulp extension models as shown in - Figs. 12 and 13. Nanocomposite resin inlay/onlay transmitted almost all stresses to the surrounding dental structures, while LDS inlay/onlay absorbed most of the stresses within the restoration itself. Moreover, PICN inlay/onlay transmitted fewer stresses to dental structures than nanocomposite resin restorations.

\section{Stress Distribution in Periodontal Tissues}

The pattern of stress distribution in cortical bone, spongy bone, and periodontal ligament was similar among the studied models, as shown in - Figs. 14 and 15. Stress concentrated in the cervical area of cortical bone and periodontal ligament in all models when vertical loading was applied, as shown in -Fig. 14. Oblique loading was associated with higher stress concentration in periodontal tissues and greater von Mises values than vertical loading, as observed in -Figs. 15-17. Von Mises values in periodontal structures when vertical and oblique loadings were applied are summarized in -Figs. 16 and 17.

\section{Discussion}

The ideal coronal restoration of endodontically treated teeth aims to preserve the root canal system, support the 


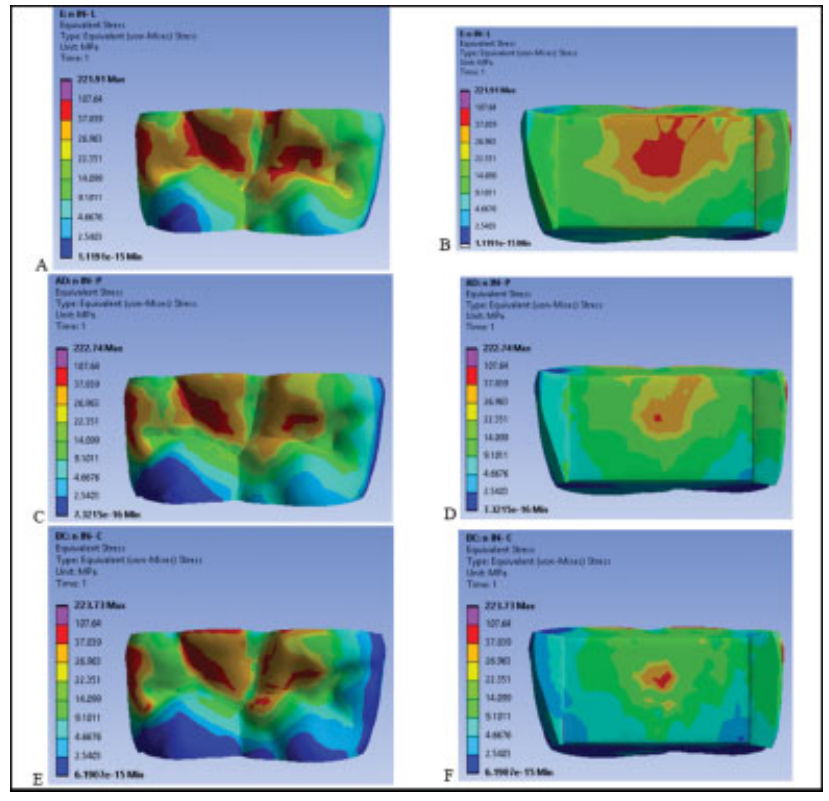

Fig. 7 Stress distribution in conventional inlay without pulp extension when vertical load was applied. (A, B) LSD inlay (L1 model); (C, D) PICN inlay (P1 model); (E, F) nanocomposite inlay (C1 model).

remaining structures, and replace the lost tooth structures. $^{35}$ The anatomic position of the tooth, the occlusal forces on it, its restorative requirements, ${ }^{36}$ as well as the properties of the restorative material, ${ }^{14}$ are important factors that should be taken into account when endodontically treated teeth are to be restored. ${ }^{36}$ Thanks to adhesive dentistry, inlays and onlays, which are made from different

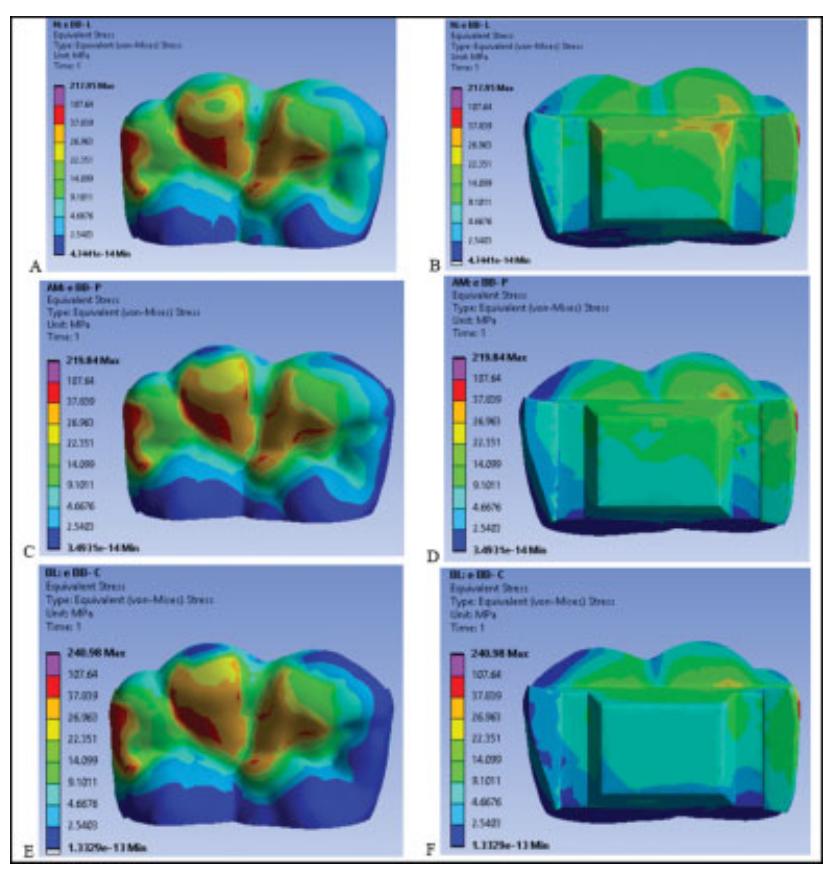

Fig. 8 Stress distribution in modified onlay (covered buccal cusps) with pulp extension when vertical load was applied. (A, B) LDS onlay (L5 model); (C, D) PICN onlay (P5 model); (E, F) nanocomposite onlay (C5 model).

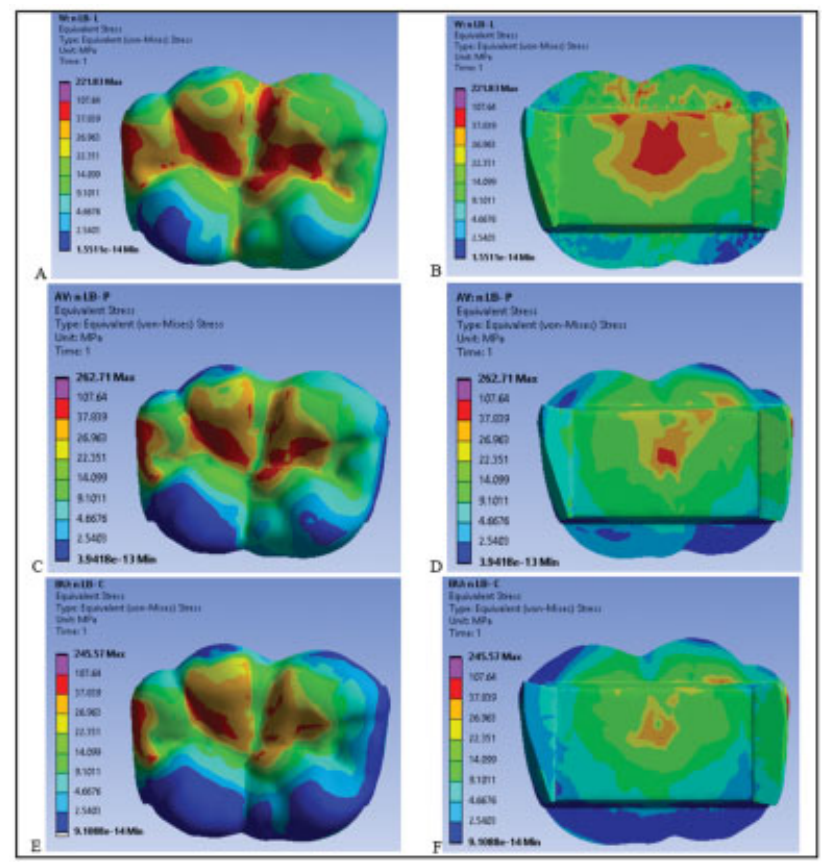

Fig. 9 Stress distribution in conventional onlay (covered all cusps) without pulp extension when vertical load was applied. (A, B) LDS onlay (L3 model); (C, D) PICN onlay (P3 model); (E, F) nanocomposite onlay (C3 model).

cosmetic materials, provide conservative alternatives for such teeth. ${ }^{11}$ However, the final conclusion about inlay/onlay designs and materials is still controversial. ${ }^{13,22}$ Finite element analysis is a popular numerical method for

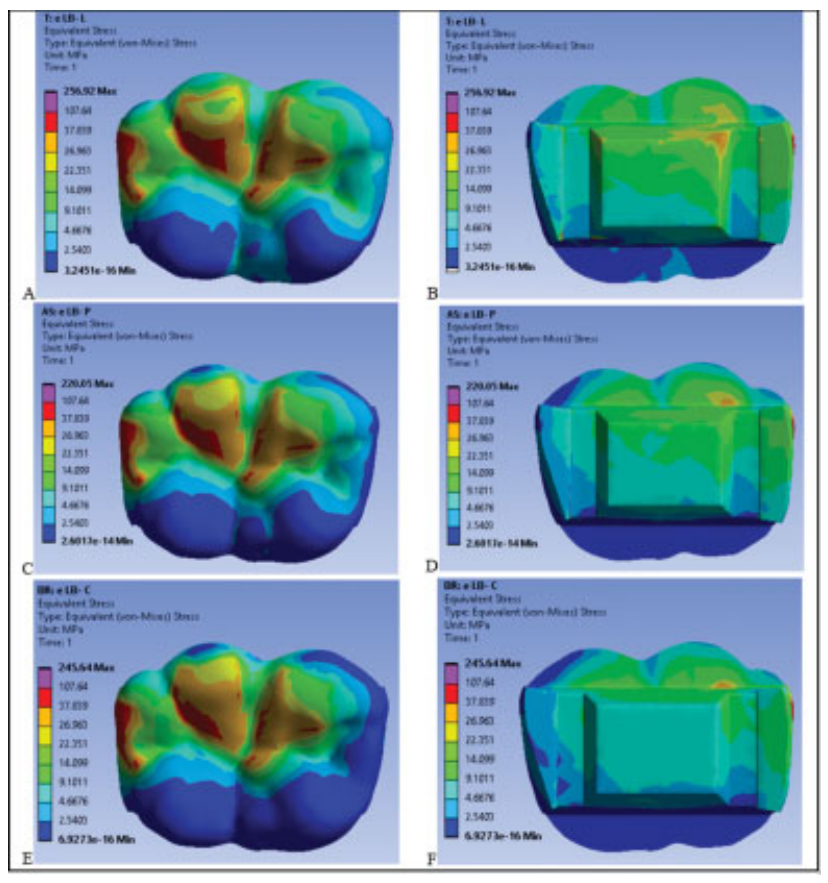

Fig. 10 Stress distribution in modified onlay (covered all cusps) with pulp extension when vertical load was applied. (A, B) LDS onlay (L6 model); (C, D) PICN onlay (P6 model); (E, F) nanocomposite onlay (C6 model). 


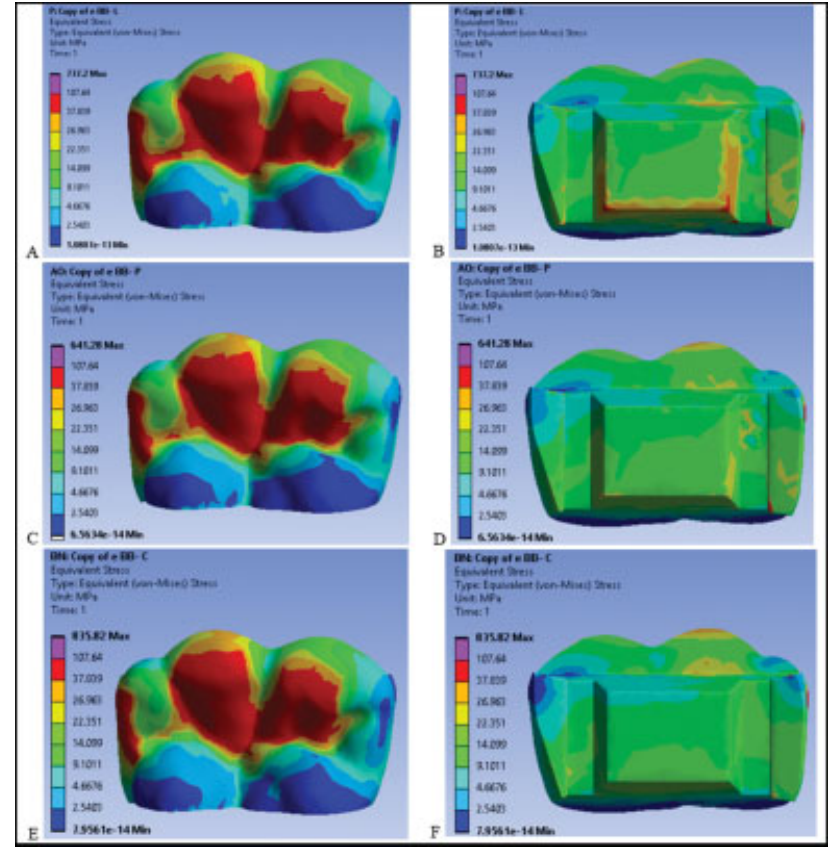

Fig. 11 Stress distribution in modified onlay (covered buccal cusps) with pulp extension when oblique load was applied. (A, B) LDS onlay (L5 model); (C, D) PICN onlay (P5 model); (E, F) nanocomposite onlay (C5 model).

stress analysis that has been used effectively in dentistry since 1970. This method is considered as an essential search tool, by which researchers are able to determine the stress distribution in tooth-restoration complex under different circumstances. ${ }^{37}$ Therefore, this study aimed to assess the effect of diverse designs and materials of inlays and onlays on stress distribution in mandibular molars when vertical and oblique loadings were applied.

Mandibular molar models with MOD cavities were used in this study, as posterior teeth are more likely to lose hard tissues because of caries, restoration failure, or endodontic treatment procedures. ${ }^{14}$ Furthermore, posterior teeth are subjected to functional and parafunctional forces of various directions and magnitudes. ${ }^{14}$ The maximum bite force ranges from $200 \mathrm{~N}$ to $3,500 \mathrm{~N}$ according to many factors such as the occlusion scheme, the existed restorations, and the position of the tooth. Commonly, the normal bite force on molars varies from 400 to $800 \mathrm{~N} .^{34}$ Therefore, an average force of $600 \mathrm{~N}$ was applied in this study.

Because mandibular molars are subjected to different directions of forces as mentioned above, vertical loading was applied to stimulate the normal force on mandibular molars, whereas oblique loading was applied to stimulate the clinical force acting on mandibular molars during the closing phase of mastication. ${ }^{14}$ In our study, oblique loading caused greater stress concentration and higher values in dental tissues and restoration in all models, as shown in -Figs. 4,5,6 and 13. This finding endorses the results of earlier studies that found oblique forces to generate higher stresses in the remaining dental structures and restorations than vertical loads. ${ }^{8,31,34}$

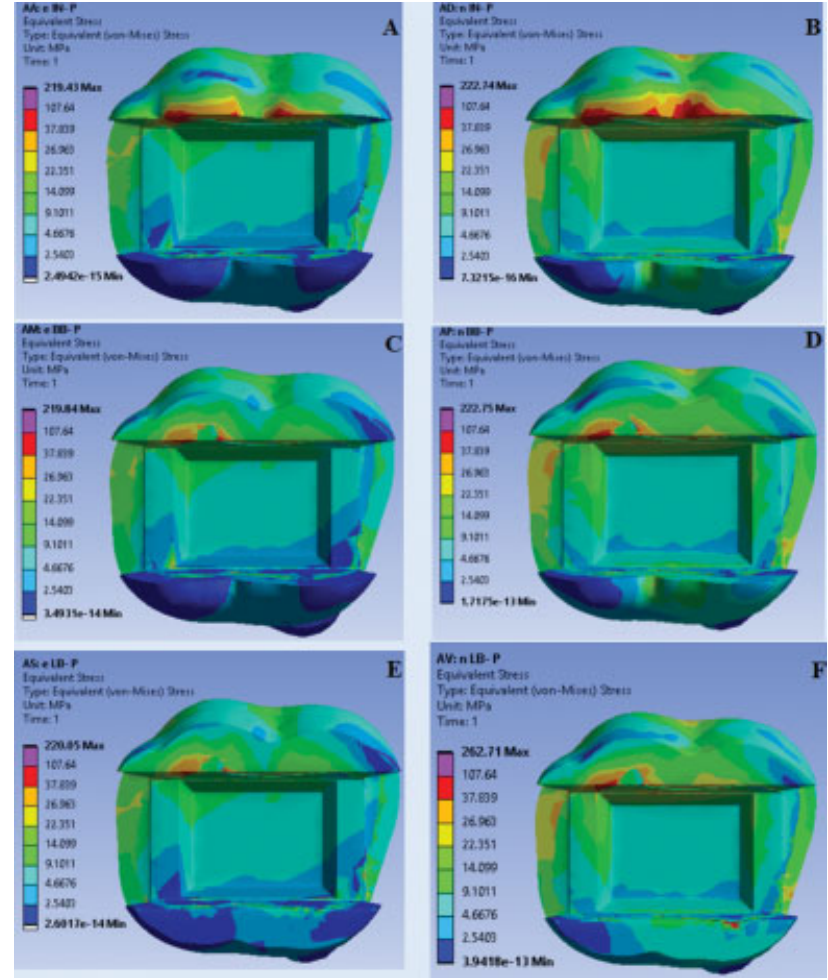

Fig. 12 Stress distribution in dental structures restored by PICN restorations when vertical load was applied (occlusal view). (A) Modified inlay with pulp extension model. (B) Conventional inlay without pulp extension model. (C) Modified onlay that covered buccal cusps model. (D) Conventional onlay that covered buccal cusps model. (E) Modified onlay that covered all cusps model. (F) Conventional onlay that covered all cusps model.

The cervical region showed stress concentration especially on the distal side under two loadings. Stress concentration in the cervical region of the tooth might refer to an interaction between this area and surrounding bone, as stress concentration was also seen in the cervical region of the cortical bone. Moreover, the oblique loading caused higher stresses in the roots that may lead to root failure because the tooth is endodontically treated. These findings correspond to the results of previous studies. ${ }^{8,31}$ Stress concentration was also seen in the loading points on restoration in onlay models or adjacent enamel in inlay models, which is consistent with other studies such as in the study by Holberg et $\mathrm{al}^{12}$ who concluded that compressive stresses occurred in the loading areas, while tensile stress was in the surrounding regions.

Regarding the restoration design, the results of von Mises maps showed that stress concentration in modified inlays/onlays with pulp extension was less than that in conventional inlays/onlays without pulp extension. This could be explained by the thickness of the restoration and its volume. ${ }^{32}$ The increase in the thickness and volume of the restoration corresponds to a better pattern of stress distribution; our finding is in line with the conclusions of previous studies, ${ }^{32,38}$ which found that increasing the volume of the restoration was associated with a better pattern of stress distribution in dental structures and restorations. In 


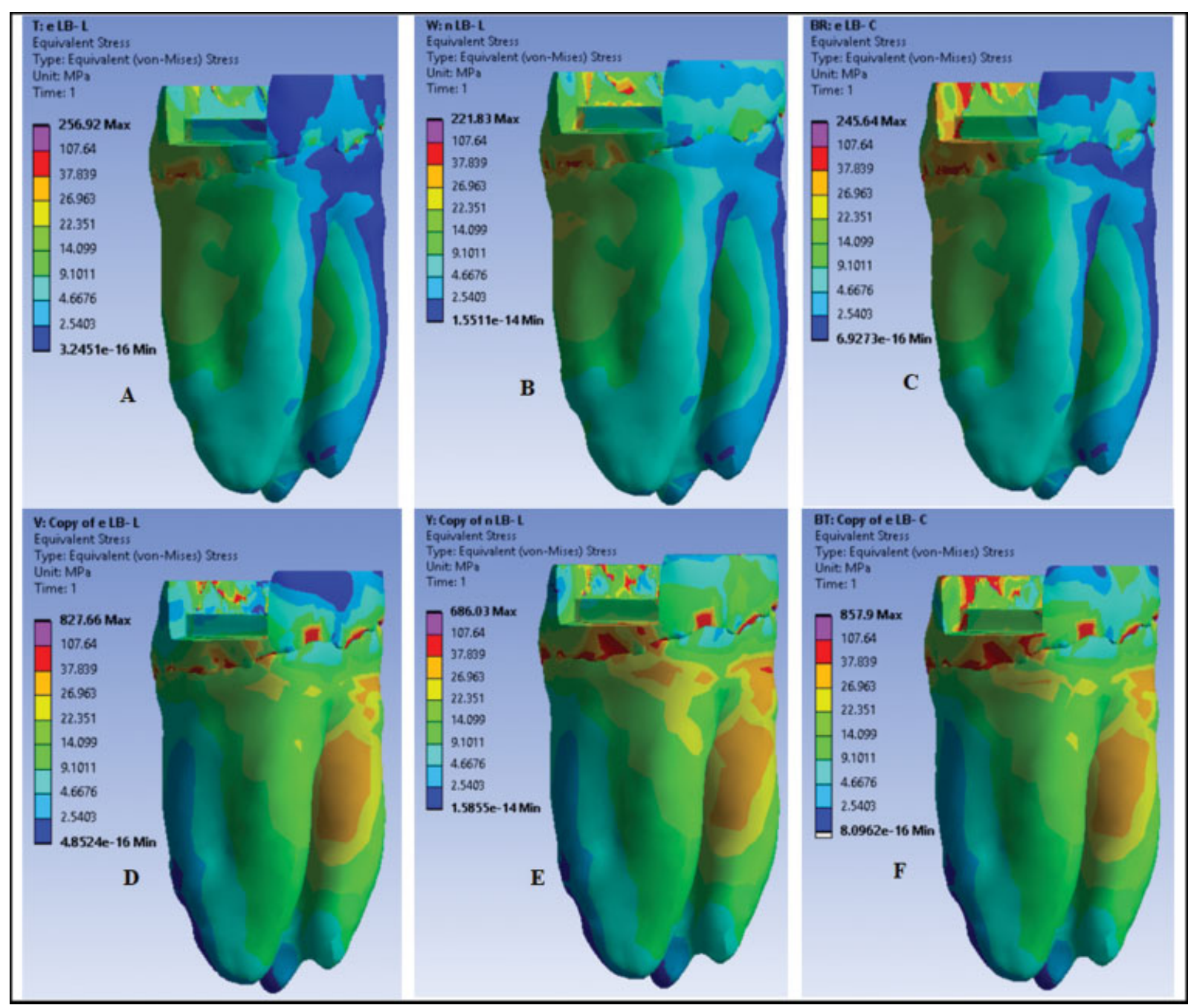

Fig. 13 Stress distribution in dental structures restored by onlay (covered all cusps). (A-C) Modified LDS onlay, conventional LDS onlay, and modified nanocomposite onlay models, respectively, when vertical load was applied. (D-F) Modified LDS onlay, conventional LDS onlay, and modified nanocomposite onlay models, respectively, when oblique load was applied.

contrast, stresses are concentrated in the internal surfaces of conventional inlays/onlays without pulp extension. The stress in the base of inlays/onlays may be an indicator of the potential failure; it is thought to be responsible for crack initiation that might lead to fracture of the restoration bulk. ${ }^{39}$ More stresses are also concentrated in the surrounding dental structures that were restored by conventional inlays/onlays compared with modified inlay/onlay with pulp extension models. This might be attributed to the decrease in the thickness of the restorative material. ${ }^{39}$ Moreover, the RMGI base might cause stress transmission to the adjacent structures in conventional inlay/onlay models due to its low elastic modulus.

Taking into account no cuspal coverage, inlays showed the highest von Mises values and the highest stress concentration; this is in accordance with the study by Dejak and Młotkowski. ${ }^{13}$ Furthermore, inlay models showed higher stress concentration in tooth cusps and the internal walls of the cavity as shown in - Fig. 12; this might be explained by the location of the loading points. In inlay models, the loadings were partially applied on the tooth structures, while they were applied totally to the onlays that absorbed most of the loads. ${ }^{31}$ Because of the stress location in inlay-restored teeth, the likely damage would occur in the tooth-inlay interface. Secondary caries and debonding may be the potential failure in inlay-restored teeth. A systematic review showed that caries, fracture of the tooth, and fracture or chipping of ceramic were the most frequent complications of inlays and onlays. ${ }^{9}$ Fracture of tooth structures might be the widespread complication of composite resin inlay-restored teeth because composite resin inlays are susceptible to high wear over time. This wear causes a decrease in the height of the restoration and makes the forces act mainly on the tooth. However, as ceramic has high wear resistance, ceramic inlays receive the main forces that may cause ceramic chipping. ${ }^{13}$ The wear of the PICN is in the same range of ceramic wear (IPS e.max CAD) according to the manufacturer; ${ }^{40}$ therefore, PICN inlays might show chipping of restoration, same as ceramic inlays rather than tooth fracture. On the contrary, the forces were totally on the restoration in onlay models, 


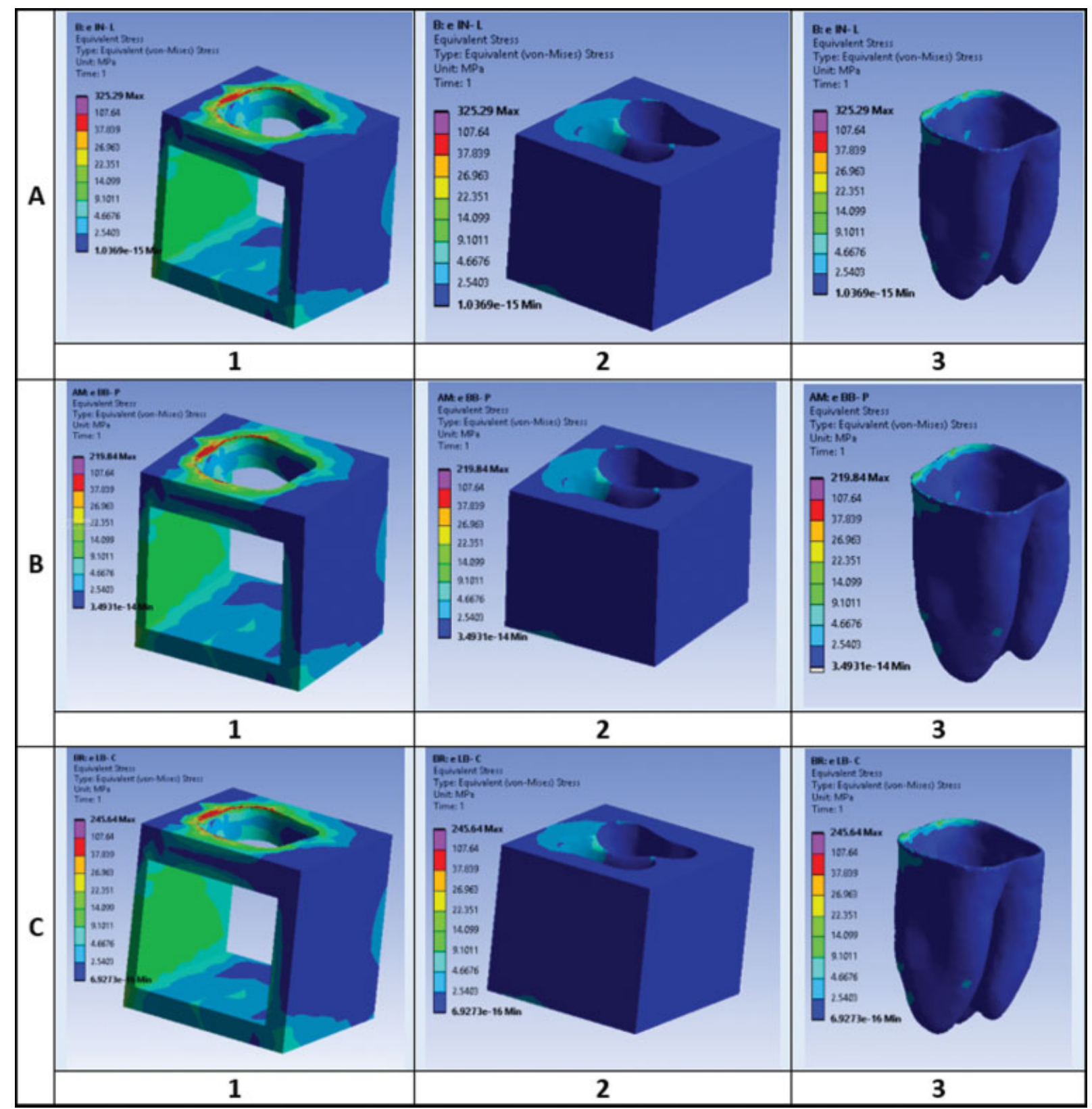

Fig. 14 Stress distribution in periodontal tissues when vertical load was applied in modified restoration models. (A) LDS inlay model. (B) PICN onlay (covered buccal cusps) model. (C) Nanocomposite onlay (covered all cusps) model. 1: cortical bone; 2: spongy bone; 3: periodontal ligament.

which protects onlay margins from chipping ${ }^{31}$ and protects the tooth from damage. ${ }^{13}$ This could clarify why stress distribution was more preferable in onlay models than in inlay models; this corresponds with the results of previous studies that found inlays were associated with higher stress concentration than onlays. ${ }^{8,13}$

According to the restorative material and regardless of the design of the restoration, lithium disilicate ceramic inlays and onlays showed the highest von Mises values and the highest stress concentration within the restoration itself, whereas nanocomposite resin inlays and onlays showed the lowest von Mises values as well as the least stress concentration in the restoration. This can be attributed to the elastic module of these materials. The higher the elastic modulus the restorative material has, the greater stress concentrates in the restoration, and the less stress is transmitted to the dental structures. ${ }^{8,31,38}$ Although Jiang et $\mathrm{al}^{8}$ concluded that composite resin is better than ceramic in terms of stress redistribution in the prepared cavity, we found that the highest stress concentration in dental structures was in composite resin models. It could be due to the low elastic modulus of composite resin that caused stress transmission to the dental tissues. Correspondingly, lithium disilicate ceramic models showed the least stress concentration in dental structures because of the high elastic modulus of lithium disilicate glass-ceramic. ${ }^{31,38}$ PICN inlays and 


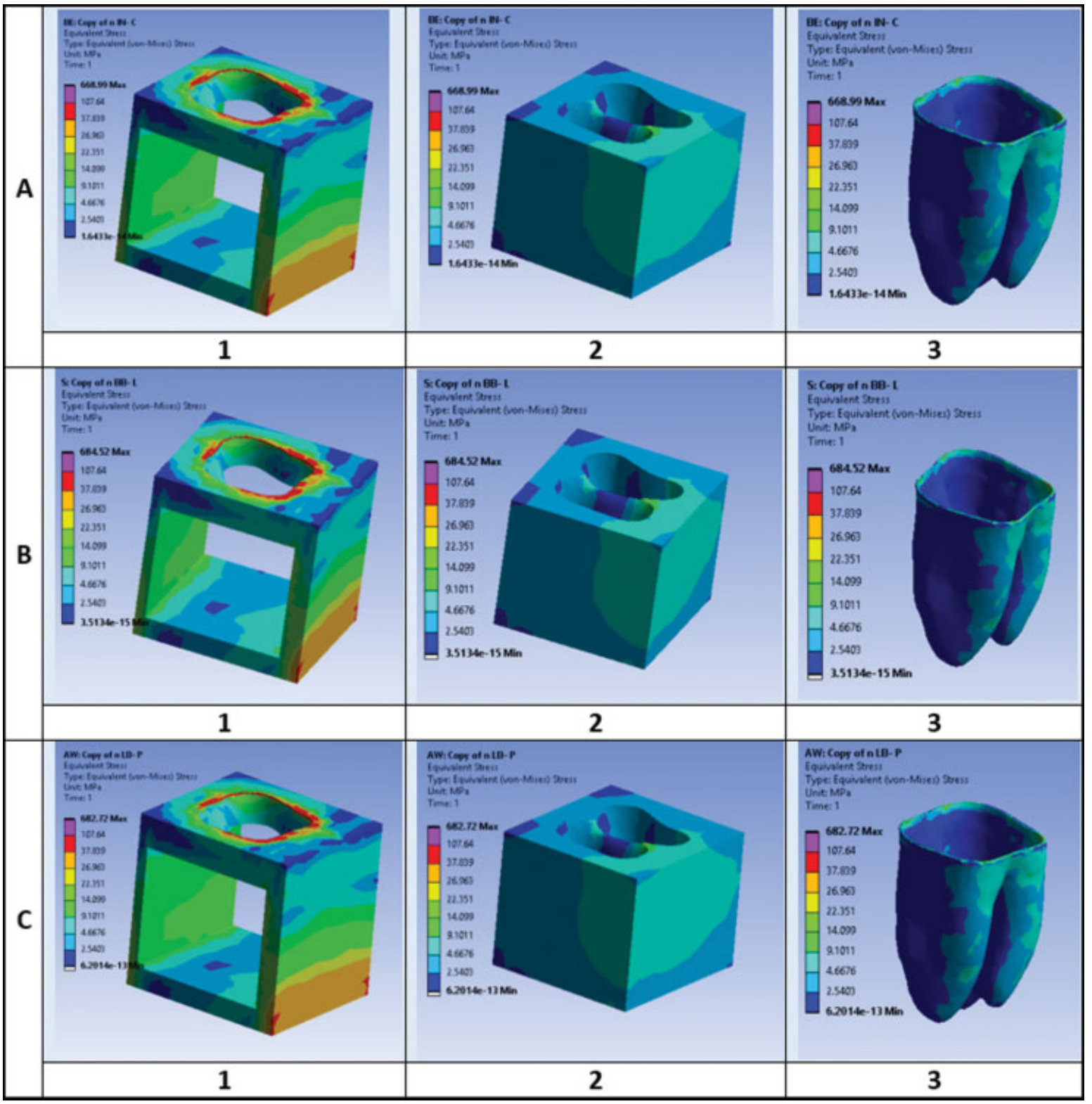

Fig. 15 Stress distribution in periodontal tissues when oblique load was applied in conventional restoration models. (A) Nanocomposite inlay model. (B) LDS onlay (covered buccal cusps) model. (C) PICN onlay (covered all cusps) model. 1: cortical bone; 2: spongy bone; 3: periodontal ligament.

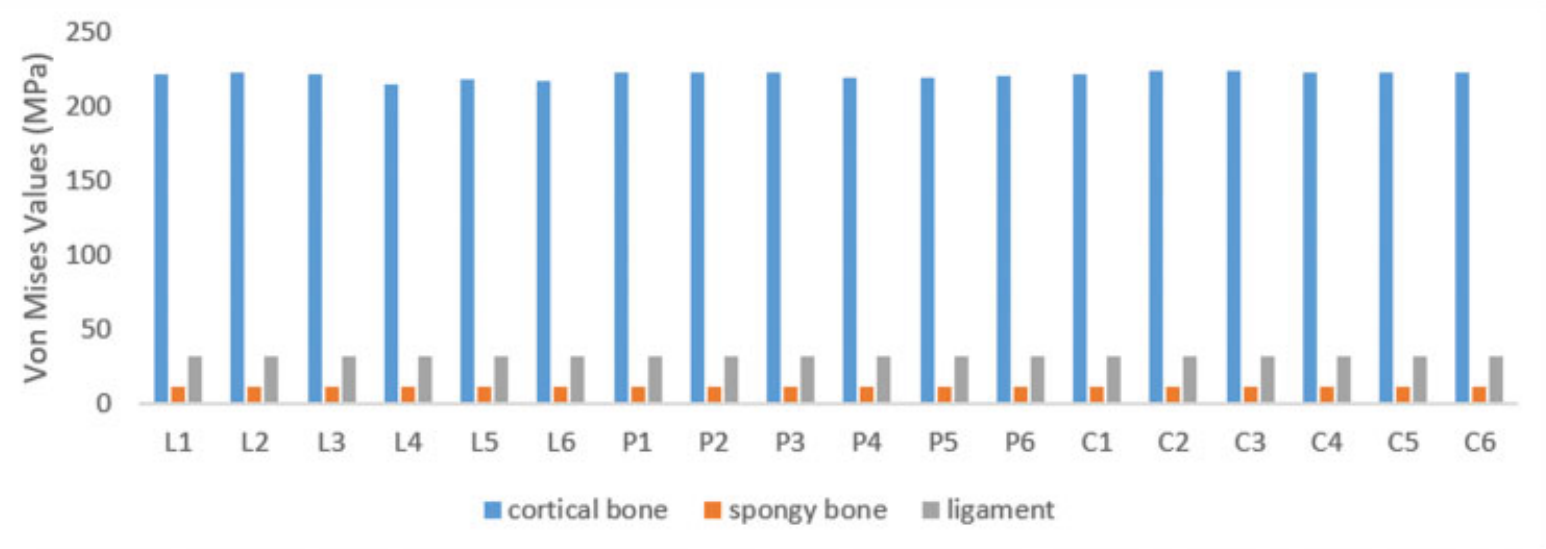

Fig. 16 von Mises values in periodontal tissues when vertical load was applied; L1-L6: LDS restoration models. P1-P6: PICN restoration models. C1-C6: nanocomposite resin restoration models. 


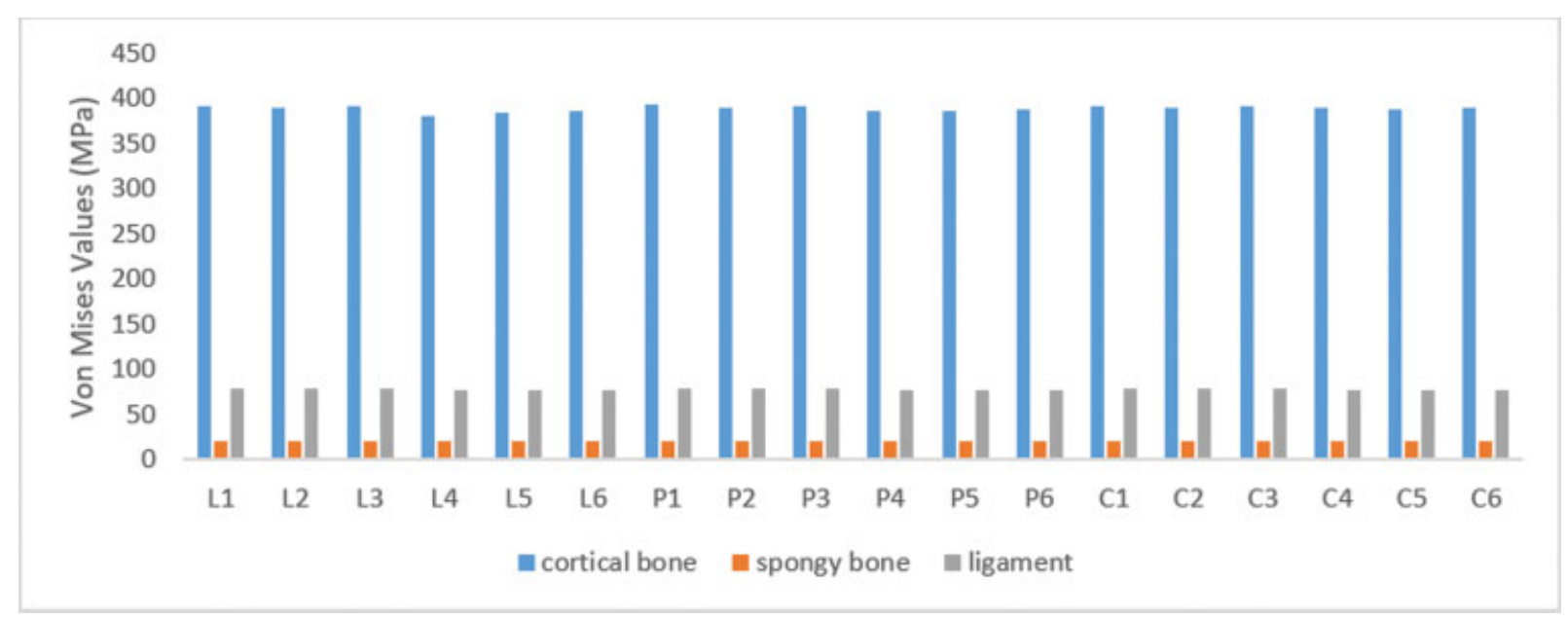

Fig. 17 von Mises values in periodontal tissues when oblique load was applied; L1-L6: LDS restoration models. P1-P6: PICN restoration models. C1-C6: nanocomposite resin restoration models.

onlays showed a good pattern of stress distribution in dental structures. Therefore, PICN might be a promising alternative to glass-ceramic. However, more studies are highly suggested to be performed to make a curial decision about this material.

\section{Conclusion}

Within the limitations of this study, it has been found that modified inlays/onlays with pulp extension show a more preferable pattern of stress distribution in tooth-restoration complex than conventional inlays/onlays without pulp extension. Compared with onlays, inlays cause more stress concentration in tooth structures whether they are modified with pulp extension or not. Lithium disilicate glassceramic onlays associate with the most preferable stress distribution in dental structures among the studied models, so they are seen to be good restorations for endodontically treated molars. Nanocomposite resin restorations transmit almost all stresses to the dental structures, which might make them unsuitable choices for endodontically treated molars.

\section{Conflict of Interest}

None declared.

\section{References}

1 Souza ACO, Xavier TA, Platt JA, Borges ALS. Effect of base and inlay restorative material on the stress distribution and fracture resistance of weakened premolars. Oper Dent 2015;40(04): E158-E166

2 Lin GSS, Ghani NRNA, Noorani TY, Ismail NH. Fracture resistance of the permanent restorations for endodontically treated premolars. Eur J Gen Dent 2018;7:56-60

3 Sorensen JA, Martinoff JT. Intracoronal reinforcement and coronal coverage: a study of endodontically treated teeth. J Prosthet Dent 1984;51(06):780-784

4 Rosenstiel SF, Land MF, Fujimoto J. Contemporary Fixed Prosthodontics. 5th ed. Elsevier Health Sciences, China; 2015:890
5 Schwartz RS, Robbins JW. Post placement and restoration of endodontically treated teeth: a literature review. J Endod 2004; 30(05):289-301

6 Biacchi GR, Basting RT. Comparison of fracture strength of endocrowns and glass fiber post-retained conventional crowns. Oper Dent 2012;37(02):130-136

7 Chang CY, Kuo JS, Lin YS, Chang YH. Fracture resistance and failure modes of CEREC endo-crowns and conventional post and coresupported CEREC crowns. J Dent Sci 2009;4:110-117

8 Jiang W, Bo H, Yongchun G, LongXing N. Stress distribution in molars restored with inlays or onlays with or without endodontic treatment: a three-dimensional finite element analysis. J Prosthet Dent 2010;103(01):6-12

9 Morimoto S, Rebello de Sampaio FBW, Braga MM, Sesma N, Özcan M. Survival rate of resin and ceramic inlays, onlays, and overlays: a systematic review and meta-analysis. J Dent Res 2016;95(09): 985-994

10 Seow LL, Toh CG, Wilson NH. Strain measurements and fracture resistance of endodontically treated premolars restored with allceramic restorations. J Dent 2015;43(01):126-132

11 Oen KT, Veitz-Keenan A, Spivakovsky S, Wong YJ, Bakarman E, Yip J. CAD/CAM versus traditional indirect methods in the fabrication of inlays, onlays, and crowns. Cochrane Database Syst Rev 2014: CD011063

12 Holberg C, Winterhalder P, Wichelhaus A, Hickel R, Huth K. Fracture risk of lithium-disilicate ceramic inlays: a finite element analysis. Dent Mater 2013;29(12):1244-1250

13 Dejak B, Młotkowski A. A comparison of mvM stress of inlays, onlays and endocrowns made from various materials and their bonding with molars in a computer simulation of mastication FEA. Dent Mater 2020;36(07):854-864

14 Çelik Köycü B, Imirzalioğlu P, Özden UA. Three-dimensional finite element analysis of stress distribution in inlay-restored mandibular first molar under simultaneous thermomechanical loads. Dent Mater J 2016;35(02):180-186

15 Mitra SB, Wu D, Holmes BN. An application of nanotechnology in advanced dental materials. J Am Dent Assoc 2003;134(10): $1382-1390$

16 Hopp CD, Land MF. Considerations for ceramic inlays in posterior teeth: a review. Clin Cosmet Investig Dent 2013;5:21-32

17 McLaren EA, Cao PT. Ceramics in dentistry-part I: classes of materials. Inside Dentistry 2009;5(09):94-104

18 Gracis S, Thompson VP, Ferencz JL, Silva NR, Bonfante EA. A new classification system for all-ceramic and ceramic-like restorative materials. Int J Prosthodont 2015;28(03):227-235 
19 Li W, Sun J. Effects of ceramic density and sintering temperature on the mechanical properties of a novel polymer-infiltrated ceramic-network zirconia dental restorative (filling) material. Med Sci Monit 2018;24:3068-3076

20 Cubas GB, Camacho GB, Pereira-Cenci T, Nonaka T, Barbin EL. Influence of cavity design and restorative material on the fracture resistance of maxillary premolars. Gen Dent 2010;58(02):e84-e88

21 Liu X, Fok A, Li H. Influence of restorative material and proximal cavity design on the fracture resistance of MOD inlay restoration. Dent Mater 2014;30(03):327-333

22 Magne P, Oganesyan T. Premolar cuspal flexure as a function of restorative material and occlusal contact location. Quintessence Int 2009;40(05):363-370

23 St-Georges AJ, Sturdevant JR, Swift EJ Jr, Thompson JY. Fracture resistance of prepared teeth restored with bonded inlay restorations. J Prosthet Dent 2003;89(06):551-557

24 Menicucci G, Mossolov A, Mozzati M, Lorenzetti M, Preti G. Toothimplant connection: some biomechanical aspects based on finite element analyses. Clin Oral Implants Res 2002;13(03):334-341

25 D'souza KM, Aras MA. Three-dimensional finite element analysis of the stress distribution pattern in a mandibular first molar tooth restored with five different restorative materials. J Indian Prosthodont Soc 2017;17(01):53-60

26 Meijer HJA, Kuiper JH, Starmans FJM, Bosman F. Stress distribution around dental implants: influence of superstructure, length of implants, and height of mandible. J Prosthet Dent 1992;68(01): 96-102

27 Jiang Q, Huang Y, Tu X, Li Z, He Y, Yang X. Biomechanical properties of first maxillary molars with different endodontic cavities: a finite element analysis. J Endod 2018;44(08):1283-1288

28 Belli R, Wendler M, de Ligny D, et al. Chairside CAD/CAM materials. Part 1: Measurement of elastic constants and microstructural characterization. Dent Mater 2017;33(01):84-98

29 Romeed SA, Dunne SM. Stress analysis of different post-luting systems: a three-dimensional finite element analysis. Aust Dent J 2013;58(01):82-88
30 Rodrigues SA Jr, Scherrer SS, Ferracane JL, Della Bona A. Microstructural characterization and fracture behavior of a microhybrid and a nanofill composite. Dent Mater 2008;24(09): 1281-1288

31 Yamanel K, Çaglar A, Gülsahi K, Özden UA. Effects of different ceramic and composite materials on stress distribution in inlay and onlay cavities: 3-D finite element analysis. Dent Mater J 2009; 28(06):661-670

32 Gulec L, Ulusoy N. Effect of endocrown restorations with different CAD/CAM materials: 3D finite element and weibull analyses. BioMed Res Int 2017;2017:5638683

33 Yang HS, Lang LA, Guckes AD, Felton DA. The effect of thermal change on various dowel-and-core restorative materials. J Prosthet Dent 2001;86(01):74-80

34 Mei ML, Chen YM, Li H, Chu CH. Influence of the indirect restoration design on the fracture resistance: a finite element study. Biomed Eng Online 2016;15:3

35 Coldea A, Swain MV, Thiel N. Mechanical properties of polymerinfiltrated-ceramic-network materials. Dent Mater 2013;29(04): 419-426

36 Hargreaves KM, Berman LH. Cohen's pathways of the pulp. 11th ed. Elsevier Health Sciences, Canada; 2015:1143

37 Srirekha A, Bashetty K. Infinite to finite: an overview of finite element analysis. Indian J Dent Res 2010;21(03): 425-432

38 Durand LB, Guimarães JC, Monteiro Junior S, Baratieri LN. Effect of ceramic thickness and composite bases on stress distribution of inlays-a finite element analysis. Braz Dent J 2015;26(02): 146-151

39 Ona M, Watanabe C, Igarashi Y, Wakabayashi N. Influence of preparation design on failure risks of ceramic inlays: a finite element analysis. J Adhes Dent 2011;13(04):367-373

40 Leung BT, Tsoi JK, Matinlinna JP, Pow EH. Comparison of mechanical properties of three machinable ceramics with an experimental fluorophlogopite glass ceramic. J Prosthet Dent 2015;114(03): 440-446 